\title{
Management of a caseous lymphadenitis outbreak in a new Iberian ibex (Capra pyrenaica) stock reservoir
}

Andreu Colom-Cadena ${ }^{1}$, Roser Velarde ${ }^{1}$, Jess Salinas ${ }^{2}$, Carmen Borge ${ }^{3}$, Ignacio Garca-Bocanegra ${ }^{3}$, Emmanuel Serrano 1,4, Diana Gass 1, Ester Bach', Encarna Casas-Daz 1, Jorge R Lpez-Olvera 1, Santiago Lavn ${ }^{\text {, }}$ Lus Len-Vizcano ${ }^{2}$ and Gregorio Mentaberre ${ }^{*^{*}}$

\begin{abstract}
Background: In 2010, an Iberian ibex (Capra pyrenaica hispanica) stock reservoir was established for conservation purposes in north-eastern Spain. Eighteen ibexes were captured in the wild and housed in a 17 hectare enclosure. Once in captivity, a caseous lymphadenitis (CLA) outbreak occurred and ibex handlings were carried out at six-month intervals between 2010 and 2013 to perform health examinations and sampling. Treatment with a bacterin-based autovaccine and penicillin $\mathrm{G}$ benzatine was added during the third and subsequent handlings, when infection by Corynebacterium pseudotuberculosis was confirmed. Changes in lesion score, serum anti-C. pseudotuberculosis antibodies and haematological parameters were analyzed to assess captivity effects, disease emergence and treatment efficacy. Serum acute phase proteins (APP) Haptoglobin (Hp), Amyloid A (SAA) and Acid Soluble Glycoprotein (ASG) concentrations were also determined to evaluate their usefulness as indicators of clinical status.

Once in captivity, 12 out of 14 ibexes (85.7\%) seroconverted, preceding the emergence of clinical signs; moreover, TP, WBC, eosinophil and platelet cell counts increased while monocyte and basophil cell counts decreased. After treatment, casualties and fistulas disappeared and both packed cell volume (PCV) and haemoglobin concentration significantly increased. Hp, SAA and ASG values were under the limit of detection or showed no significant differences.
\end{abstract}

Conclusions: A role for captivity in contagion rate is suggested by the increase in antibody levels against C. pseudotuberculosis and the emergence of clinical signs. Although boosted by captivity, this is the first report of an outbreak of caseous lymphadenitis displaying high morbidity and mortality in wild ungulates. Treatment consisting of both vaccination and antibiotic therapy seemed to prevent mortality and alleviate disease severity, but was not reflected in the humoural response. Haematology and APP were not useful indicators in our study, perhaps due to the sampling frequency. Presumably endemic and irrelevant in the wild, this common disease of domestic small ruminants is complicating conservation efforts for the Iberian ibex in north-eastern Spain.

Keywords: Capra pyrenaica, Corynebacterium pseudotuberculosis, Caseous lymphadenitis, Antibodies, Autovaccine, Acute phase proteins

\footnotetext{
* Correspondence: gregorio.mentaberres@uab.cat

${ }^{1}$ Servei d Ecopatologia de Fauna Salvatge (SEFaS), Departament de Medicina

i Cirurgia Animals, Facultat de Veterinria, Universitat Autnoma de Barcelona (UAB), 08193 Bellaterra, Spain

Full list of author information is available at the end of the article
} 


\section{Background}

Corynebacterium pseudotuberculosis causes widespread abscesses in the lymph nodes, subcutaneous tissues and internal organs of buffaloes, wild ruminants, camels, cattle and horses [1-3]. It is the causative agent of caseous lymphadenitis (CLA), a disease occurring worldwide that primarily affects domestic small ruminants [4]. In wildlife, C. pseudotuberculosis has been previously described as isolated cases in pronghorns (Antilocapra americana) [5], elk (Cervus elaphus canadensis) [6] and Arabian oryx (Oryx leucoryx) [7], or as chance findings during routine meat inspection of antelope carcasses from a South African game reserve [8]. Human infection is also possible but unusual, being mostly related to occupational exposure [9]. C. pseudotuberculosis infection occurs through the oral, nasal and ocular mucosa, or through skin wounds. The bacterium can survive up to eight months in faeces, fomites or in the soil, a fact that favours its maintenance in small ruminant flocks worldwide. The principal clinical sign of CLA in sheep and goat is lymph node abscessation, which may be closed or fistulised, discharging pus and contaminating the environment. Infected animals without clinical signs also can shed bacteria through their respiratory tract and mechanical vectors such as flies have also been described to play a role $[1,10]$.

Economic losses due to CLA are an important issue in the sheep and goat industries because of the reduction in wool, meat and milk production, the decrease of reproductive rates and the losses due to condemnation of carcasses and skins in abattoirs [1,10]. Lamentably, classical serological tests show inadequate sensitivity or specificity to detect contact with C. pseudotuberculosis [1], making disease detection difficult. Nevertheless, some enzyme-linked immunoabsorbent assay (ELISA) diagnostic tests have been observed to be effective in control and eradication programs, especially those based on phospholipase D (PLD) as an antigen [11,12]. Recently developed ELISA tests based on the detection of gamma interferon (IFN- $\gamma$ ) appear to be more sensitive in detecting early infection [12,13].

Disease management in sheep flocks is based on lancing and flushing-out or the surgical removal of lesions accompanied by topical disinfection and parenteral antibiotic treatment for 46 weeks $[4,10]$. Special care must be taken to prevent environmental contamination during drainage of the abscesses [10]. The effectiveness of such management measures strongly relies on the close surveillance of new infections, which is very difficult due the above-mentioned limitations in disease diagnosis. Vaccination has been the main strategy for CLA control in countries where the disease is endemic. Several vaccines have been developed and used with varied outcomes. The earliest ones consisted of bacterin-based vaccines, which initially displayed limited efficacy [14] but have improved over time $[15,16]$. The ability of PLD to protect against CLA encouraged toxoid vaccine studies [17], and combined bacterin-toxoid vaccines have also been used with success [18]. Live vaccines also elicit strong humoural and cell-mediated immune responses in goats and sheep [1,19]. Finally, the use of autogenous vaccines has been supported both in the literature and by veterinary practitioners for the treatment of CLA at herd level [20].

The Iberian ibex (Capra pyrenaica) is an endemic wild ruminant of the Iberian Peninsula, whose range is expanding both in Spain and Portugal [21-23]. The Red List of Threatened Species of the International Union for Conservation of Nature (IUCN) considers the status of C. pyrenaica hispanica to be of Least Concern (LC) [23]. However, threats such as fragmentation, competition with domestic livestock and other introduced wild ungulates or illegal hunting occur [24]. In addition, diseases have been one of the main factors responsible for demographic changes in the recent history of this species. The impact of sarcoptic mange, caused by Sarcoptes scabei, has been of particular relevance, causing mortalities of over 95\% in ibex populations in southern Spain [25]. Other pathogens, such as Mycoplasma agalactiae, have caused less severe outbreaks in some Iberian ibex populations [26]. This is both a conservation issue and an economic concern in those regions where game exploitation (trophy hunting) of this valuable species occurs [27]. Hence, because of the biological value of this species and the ever present risk of game cessation due to disease outbreaks, the creation of stock reservoirs of Iberian ibexes have been promoted by the environmental agencies of the Spanish government in the main areas of distribution of this species (i.e., Sierra Nevada, Sierra de Cazorla and Serrana de Cuenca Natural Parks in southern and central Spain, respectively). In 2010, the threatening south north advance of sarcoptic mange in the Iberian Peninsula prompted the decision to create a new stock reservoir of Iberian ibexes in the, up to date, sarcoptic mangefree subpopulation of the National Game Reserve of the Ports de Tortosa i Beseit (NGRPTB). This study analyzes the role of captivity in the development of a CLA outbreak that occurred in this new captive population and evaluates the effect of a CLA vaccine-based treatment on the occurrence of clinical signs, the immune humoural response, changes in haematological parameters, and acute phase protein (APP) concentrations.

\section{Materials and methods}

\section{Study area and period}

The study area is situated in the NGRPTB (4048 $28 \mathrm{~N}$, 01917 E), in Catalonia, north-eastern Spain. Specifically, this study was carried out in an enclosure of 17 hectares 
within the NGRPTB aimed at housing a stock reservoir of Iberian ibex. The facilities consist of a double peripheral fence, to prevent contact with animals outside of the fence, a quarantine area, a warehouse and a smaller fenced area with troughs and connected to a capture corral trap. The study was carried out between March 2010 and January 2013.

\section{Animals and samples The founding ibex population}

Eighteen ibexes were captured in 2010 (t0) by means of seven fixed box-traps scattered throughout the NGRPTB. Once trapped, the ibexes were darted by means of a blowpipe and anaesthetized with a combination of xylazine (3 mg/kg; Xilagesic 20\%, $200 \mathrm{mg} / \mathrm{ml}$, Laboratorios Calier, Barcelona, Spain) and ketamine (3 mg/kg; Imalgene 1000, $100 \mathrm{mg} / \mathrm{ml}$, Merial, Lyon, France) [28]. One ibex died during transport from the box-trap site to the enclosure. Another ibex died once in captivity (between to and t1) and two escaped from the enclosure before the first handling (t1). On the other hand, two newborn ibexes from females captured pregnant in the wild added to the founding population within the enclosure between $\mathrm{t} 0$ and t1. Hence, sixteen ibexes, ten females and six males aged one to eleven years, were used for our longitudinal studies. Two of these ibexes were euthanized between $\mathrm{t} 1$ and t2 due to draining fistulas and in order to prevent disease spread. See Table 1 to ease understanding. All the death and euthanized ibexes were necropsied. Age of adult ibexes captured in the wild was determined by horn segment counts [29]. Individual identification was done by means of both ear tags and subcutaneous passive injectable transponders of $323.8-\mathrm{mm}$ placed in the axillary area (Model Ri-Trp-RC2B, Tiris, Texas Instruments, Almelo, The Netherlands).

\section{Management of the CLA-infected ibex stock reservoir}

Routine handlings began in June 2011 (t1) and were initially planned once a year. Nevertheless, owing to the CLA outbreak and the commencement of treatment, the second and third handlings took place in December 2011 (t2) and January 2012 (t3), respectively, and continued at six month intervals until January 2013 (t5). See the detailed chronology in Figure 1. To carry out handlings, the ibexes were captured, physically restrained, blindfolded, and held in $4 \times 4 \mathrm{~cm}$ mesh sack nets (Ziboni Ornitecnica, Bergamo, Italy). The ibexes were then concentrated in a handling zone and treated with acepromazine maleate $(0.1 \mathrm{mg} / \mathrm{kg}$; Calmo Neosan, $5 \mathrm{mg} / \mathrm{ml}$, SmithKline Beecham, Madrid, Spain) to alleviate capture stress [30]. The handling protocol included collection of blood, administration of ivermectin $(0.2 \mathrm{mg} / \mathrm{kg} \mathrm{sc}$; Ivomec 1\%; Merial, Toulouse, France), checking of ear tags and microchips and an external clinical examination.
Table 1 Result of the clinical examination performed in every ibex (ID) at each handling time (t0-t5) expressed as lesion status: FL: Presence of fistulas; GLS: generalized lymph node swelling; LLS: Local lymph node swelling; NL: No apparent affectation; ND: No data

\begin{tabular}{|c|c|c|c|c|c|c|}
\hline ID & to & t1 & t2 & t3 & t4 & t5 \\
\hline 1 & $\mathrm{NL}$ & \multicolumn{5}{|c|}{ Died during transport } \\
\hline 2 & $\mathrm{NL}$ & \multicolumn{5}{|c|}{ Died into enclosure } \\
\hline 3 & $\mathrm{NL}$ & \multicolumn{5}{|c|}{ Escaped from enclosure } \\
\hline 4 & $\mathrm{NL}$ & & & & & \\
\hline 5 & $\mathrm{NL}$ & $\mathrm{NL}$ & \multicolumn{4}{|c|}{ Euthanatized into the enclosure } \\
\hline 6 & $\mathrm{NL}$ & $\mathrm{FL}$ & & & & \\
\hline 7 & $\mathrm{NL}$ & $\mathrm{FL}$ & $\mathrm{NL}$ & $\mathrm{NL}$ & $\mathrm{NL}$ & $\mathrm{NL}$ \\
\hline 8 & $\mathrm{NL}$ & GLS & $\mathrm{NL}$ & $\mathrm{NL}$ & $\mathrm{NL}$ & $\mathrm{NL}$ \\
\hline 9 & $\mathrm{NL}$ & GLS & $\mathrm{NL}$ & $\mathrm{NL}$ & $\mathrm{NL}$ & $\mathrm{NL}$ \\
\hline 10 & $\mathrm{NL}$ & GLS & GLS & LLS & $\mathrm{NL}$ & $\mathrm{NL}$ \\
\hline 11 & $\mathrm{NL}$ & LLS & LLS & LLS & $\mathrm{NL}$ & $\mathrm{NL}$ \\
\hline 12 & $\mathrm{NL}$ & LLS & LLS & $\mathrm{NL}$ & $\mathrm{NL}$ & $\mathrm{NL}$ \\
\hline 13 & $\mathrm{NL}$ & LLS & GLS & LLS & $\mathrm{NL}$ & $\mathrm{NL}$ \\
\hline 14 & $\mathrm{NL}$ & ND & $\mathrm{FL}$ & GLS & $\mathrm{NL}$ & $\mathrm{NL}$ \\
\hline 15 & $\mathrm{NL}$ & ND & LLS & LLS & $\mathrm{NL}$ & $\mathrm{NL}$ \\
\hline 16 & $\mathrm{NL}$ & LLS & LLS & LLS & $\mathrm{NL}$ & $\mathrm{NL}$ \\
\hline 17 & $\mathrm{NL}$ & ND & $\mathrm{FL}$ & GLS & LLS & ND \\
\hline 18 & $\mathrm{NL}$ & GLS & ND & LLS & $\mathrm{NL}$ & $\mathrm{NL}$ \\
\hline 19 & New born & $\mathrm{NL}$ & LLS & LLS & LLS & GLS \\
\hline 20 & & LLS & LLS & LLS & $\mathrm{NL}$ & ND \\
\hline
\end{tabular}

After CLA emergence, ibexes were also vaccinated and treated with penicillin G benzatine (1.2 million IU, intramuscular; Benzatard; Syva, Len, Spain) in each handling. Blood samples were collected from the jugular vein with disposable $10 \mathrm{ml}$ syringes fitted with $0.825 \mathrm{~mm}$. needles and processed within $12 \mathrm{~h}$ of collection. Two millilitres of each sample were placed in commercial tubes with tripotassium ethylenediaminetetraacetic acid $\left(\right.$ EDTA $\mathrm{K}_{3}$ ) as an anticoagulant. The remaining volume was placed in tubes for serum collection, allowed to clot at room temperature and centrifuged at $1800 \mathrm{~g}$. Serum was frozen at $-20 \mathrm{C}$ until testing. The purpose of clinical examination was mainly to evaluate lymph node swelling (size and texture) and included palpation and visual inspection of the superficial lymph nodes of the head, neck, shoulders and hind limbs. To reduce variability and subjectivity, all examinations were done by the same person (GM, veterinary). Four clinical categories were established in order to perform the lesion score: ibexes with no apparent lesions (NL), local lymph node swelling (LLS), generalized lymph node swelling (GLS) and ibexes with the presence of fistulised lymph nodes (FL). 


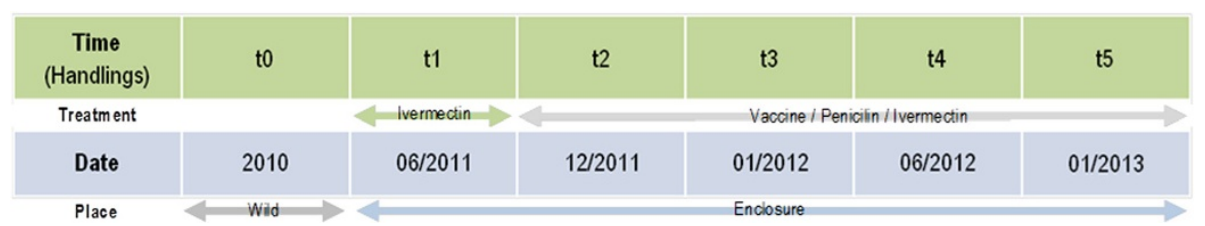

Figure 1 Diagram of the handlings dates with the corresponding treatment and location of the ibexes at each handling time.

\section{Laboratory analyses \\ Bacteriology}

Selected samples were collected from the four necropsied ibexes and from a fifth live ibex that healed after swabbing when presenting with a fistula during the t2 handling. Samples were directly cultured on blood agar base supplemented with 5\% sterile defibrinated sheep blood (Oxoid S.A., Spain). Colonies obtained after 24 $48 \mathrm{~h}$ of aerobic incubation at $37 \mathrm{C}$ were Gram-stained. Colonies of bacteria with morphological characteristics compatible with C. pseudotuberculosis were tested using API Coryne Strip (API CS; bioMrieux, France) according to the manufacturers recommendations. The API CS method involves a battery of 20 tests and the results are interpreted using the API web system (see: https:// apiweb.biomerieux.com/servlet.)

\section{Serologic analyses}

An indirect ELISA to detect C. pseudotuberculosis antibodies was performed according to Solanet et al. [31]. Two different stumps were used to acquire the antigens; one from CLA-infected farm goats from the Region of Murcia, south-eastern Spain, and the other from the CLA-infected ibexes. Six sera from domestic goats of farms free of paratuberculosis, tuberculosis and pseudotuberculosis in the Region of Murcia (Spain) were used as negative controls. Five serum samples from CLA clinical cases confirmed by histopathological and bacteriological analyses in domestic goats from the Region of Murcia were used as positive controls. Optical density (OD) was corrected by blank well lecture, and the cutoff values were calculated as the mean of negative sera OD (blank corrected) + 3 S.D. Another ELISA was done to detect antibodies against Mycobacterium bovis [32] using as the antigen the recombinant protein MPB70 from Mycobacterium bovis provided by Jim McNair (Belfast, Northern Ireland, United Kingdom). A cut-off value was calculated using ten sera obtained from ten goats in a tuberculosis-free herd (Experimental Farm, School of the Veterinary Medicine, Murcia). These negative control animals previously tested negative for tuberculosis by skin test and the IFN- $\gamma$ release assay.

Finally, a commercial ELISA kit was used to detect antibodies against Mycobacterium avium subsp. paratuberculosis -MAP- (Parachek, Prionics AG, Zurich,
Switzerland). Results were expressed as OD after reading the plates at 450 (C. pseudotuberculosis) or 405 (M. bovis and MAP) $\mathrm{nm}$ in an ELISA plate reader (DigiScan with DigiWin Software, ASYS Hitech, Austria).

\section{Haematology}

The erythrocyte (RBC), leukocyte (WBC), platelet (PLT) and differential WBC (lymphocytes [Lymph], neutrophil [Neut], eosinophil [Eos], monocyte [Mono] and basophil [Baso]) counts, and the haemoglobin concentration $(\mathrm{Hb})$ were determined by means of an automated laser analyzer (Advia 120, Bayer, Fernwald, Germany). The packed cell volume (PCV) was measured using a microPCV centrifuge (Hematospin 1400, Hawksley, Lancing, England) at $14000 \mathrm{~g}$ for $6 \mathrm{~min}$. The total protein concentration (TP) was determined by refractometry (Euromex RD 712 clinical refractometer; Euromex, Arnhem, Netherlands).

\section{Acute phase protein}

Serum concentration of haptoglobin $(\mathrm{Hp})$ was quantified using a commercial spectrophotometric assay (Phase Haptoglobin assay, Tridelta Development Ltd, Ireland). Serum amyloid A (SAA) concentration was determined with a commercial solid phase sandwich ELISA (Phase SAA assay, Tridelta Development Ltd, Ireland). Analyses were performed according to the manufacturer s instructions and the final absorbance measured in a microtitre plate reader (PowerWave XS, Bio-Tek Instruments Inc., Vermont, USA) at $630 \mathrm{~nm}$ and $450 \mathrm{~nm}$ for $\mathrm{Hp}$ and SAA, respectively. These analytical determinations were recently validated [33].

Acid soluble glycoprotein (ASG) concentration was also quantified as it correlates well with alpha-1-acid glycoprotein (AGP) in most species [34]. The ASG component of the serum samples was determined using the method described in Winzler (1955) [35], modified by Nagahata et al. [36] and Eckersall et al. [34], and optimized by Tecles et al. [37]. Briefly, serum was precipitated by mixing with perchloric acid and then centrifuged at $1750 \mathrm{~g}$ for $10 \mathrm{~min}$. Next, $20 \mu \mathrm{l}$ of supernatant was mixed with $196 \mu \mathrm{l}$ of the reagent bicinchoninic acid (Sigma chemical Company, St. Louis, Missouri, USA), the mixture incubated at $37 \mathrm{C}$ for $25 \mathrm{~s}$, and then $4 \mu \mathrm{l}$ of copper sulphate (Sigma) added as a start reagent. The protein content in the supernatant was then measured after 
325 s with a Cobas Mira Plus analyzer (ABX, Montpellier, France) at a wavelength of $550 \mathrm{~nm}$. Commercial purified bovine $\alpha 1$-acid glycoprotein (AGP; Sigma) was used as a standard. A stock solution was prepared by diluting $25 \mathrm{mg}$ of bovine AGP in $5 \mathrm{ml}$ of distilled water and a standard curve performed by mixing the stock solution with perchloric acid at a 1:4 dilution.

\section{Therapeutic intervention}

An autovaccine containing $110^{8} \mathrm{cfu} / \mathrm{ml}$ of the C. pseudotuberculosis isolated from the CLA-infected ibexes, and a strain of Archanobacterium haemolyticum previously isolated at the Department of Animal Health at the University of Crdoba, which presents strong immunogenic properties against other corynebacterial species, was elaborated (unpublished data). Briefly, C. pseudotuberculosis and $A$. haemolyticum isolates were cultivated in brain heart infusion (Oxoid, Spain) at 37C for $24 \mathrm{~h}$ and inactivated with $0.3 \%$ formaldehyde $(30-40 \% \mathrm{w} / \mathrm{v}$, Panreac, Spain). The suspension was centrifuged at $720 \mathrm{~g}$ for $15 \mathrm{~min}$ at $4 \mathrm{C}$ and the pellets re-suspended in an isotonic saline solution until the pattern 0.5 in the McFarland scale was obtained. The vaccination scheme consisted of $5 \mathrm{ml}$ subcutaneous ( $\mathrm{sc}$ ) doses ( $2 \mathrm{ml}$ for juveniles), with the first dose on December 2011 (t2) followed by revaccination one month later (t3) and subsequent doses every $6 \mathrm{~m}$, on July 2012 and January 2013 (t4 and t5, respectively). Penicillin G benzatine (1.2 million IU, intramuscular; Benzatard; Syva, Len, Spain) was administered to reduce infection progression. Penicillin G has demonstrated high action against Corynebacterium spp. in antibiograms (Personal communication).

\section{Statistical analysis}

Changes in the physiological responses (i.e., changes in haematologic parameters and APP concentration) and in anti-C. pseudotuberculosis antibody levels (i.e., Optical Density obtained by means of ELISA) of ibexes were assessed by means of a multivariate analysis of variance (MANOVA). In our case, the physiological response was defined as a canonical derived response variable named haematologic parameters (RBC, WBC, PLT, WBC, Lymph, Neut, Eos, Mono, Baso, Hb), APP (Hp, SAA, AGP), and anti-C. pseudotuberculosis antibodies (O.D. CLA-ELISA) and the explanatory factors were the handling times (from to to t5). We performed three different analyses: the first aimed to assess the early captivity effect by comparing the anti-C. pseudotuberculosis antibody levels, and the haematology and APP values between t0 and $t 1$; the second assessed the long-term captivity effect by comparing t0 with $\mathrm{t} 1-\mathrm{t} 5$; finally, for the assessment of the treatment effect, $\mathrm{t} 2$ (when the treatment started) was compared with t3 (one month later). Prior to any analysis, MANOVA assumptions (i.e., correlation between dependent variables, multivariate normality and absence of residual patterns), [38] were checked. All statistical analyses were carried out in the statistical software $\mathrm{R}$ version 3. 0. 3 (R Development Core Team 2014).

\section{Results \\ Postmortem findings}

The ibex that died during transport, the one that died in the enclosure and the two euthanized ibexes were necropsied and diagnosed with CLA on the basis of multiple abscesses and a positive C. pseudotuberculosis culture. Two additional free-living wild ibexes were diagnosed with CLA in 2005 and 2007 in the NGRPTB. All affected animals (four males, 3 to 15 years old and two females, 7 and 10 years old) had low body weights and widespread serous fat atrophy. The most frequently affected peripheral lymph nodes were those of the head (submandibular, 2/6) and neck (prescapular, 3/6). Amongst these six cases, four presented with internal dissemination of the infection with lesions seen in mediastinal lymph nodes and lungs $(4 / 6)$ as well as in mesenteric lymph nodes (3/4), kidney (2/4), spleen (1/4) and liver (1/4).

\section{Analysis of lesions score}

Results are presented in Tables 1 and 2. Clinical signs of CLA were not detected at $\mathrm{t} 0$, with pathological changes appearing between $\mathrm{t} 1$ and $\mathrm{t} 5$. Nine ibexes displayed either localized $(n=5)$ or generalized $(n=4)$ lymph node swelling at $\mathrm{t} 1$. Disease signs decreased after treatment, when no more fistulas were observed and only three ibexes displayed generalized infection. Finally, whereas generalized infection and fistulas were mostly associated with a positive CLA serological status, local and no apparent lesions were indifferently associated with a CLA positive or negative status. However, 22 out of the 24 (92\%) clinical examinations where a NL status was associated with a positive CLA serological result belonged to individuals displaying clinical signs in previous examinations. On the other hand, at least three out of the 13 clinical examinations (23\%) where a LLS status was associated with a negative CLA serological result belonged to ibexes seroconverting and/or displaying a GLS status later.

\section{Laboratory results}

At least 12 out of 14 ibexes (85.7\%) changed their serological status once within the enclosure, as shown by the significantly higher mean optical density in the CLAELISA from t1 to $t 5$ (Table 3). The antibody levels did not show significant differences once in captivity (t1-t5) (Figure 2). Three ibexes did not seroconvert during the study period whereas one ibex displayed a positive ELISA result in $\mathrm{t} 0$. Two of the ibexes that seroconverted within the enclosure changed their serological status 
Table 2 Lesions score: Number of clinical examinations performed in every handling divided by four lesion status: FL: Presence of fistulas; GLS: generalized lymph node swelling; LLS: Local lymph node swelling; NL: No apparent affectation; ND: No data

\begin{tabular}{|c|c|c|c|c|c|c|c|}
\hline & & Ibexes & $\mathrm{FL}$ & GLS & LLS & NL & ND \\
\hline t0 & & 18 & 0 & 0 & 0 & 18 & 0 \\
\hline t1 & & 16 & 2 & 4 & 5 & 2 & 3 \\
\hline t2 & & 14 & 2 & 2 & 6 & 3 & 1 \\
\hline t3 & & 14 & 0 & 2 & 8 & 4 & 0 \\
\hline t4 & & 14 & 0 & 0 & 2 & 12 & 0 \\
\hline t5 & & 14 & 0 & 1 & 0 & 11 & 2 \\
\hline \multirow[t]{2}{*}{ Period } & Wild (t0) & 18 & 0 & 0 & 0 & 18(100\%) & \\
\hline & Captivity (t1-t5) & 16 & $4(6.5 \%)$ & $9(14 \%)$ & $21(34 \%)$ & $32(52 \%)$ & \\
\hline \multirow[t]{2}{*}{ Treatment } & Before (t1-t2) & 16 & $4(18 \%)$ & $6(27 \%)$ & $11(50 \%)$ & $5(23 \%)$ & \\
\hline & After (t3-t5) & 14 & 0 & $3(7.5 \%)$ & $10(25 \%)$ & $27(67.5 \%)$ & \\
\hline \multirow[t]{2}{*}{ CLA-ELISA } & Negative & 20 & 0 & $2(22.2 \%)$ & 13(61.9\%) & $26(52 \%)$ & \\
\hline & Positive & & $4(100 \%)$ & $7(77.8 \%)$ & 8(38.1\%) & $24(48 \%)$ & \\
\hline
\end{tabular}

These clinical examinations are put into groups to show the number of ibexes observed with every lesion status and the percentage they represent (in brackets) before ( $\mathrm{t} 0$ ) and once in captivity ( $\mathrm{t} 1, \mathrm{t} 2, \mathrm{t} 3, \mathrm{t} 4, \mathrm{t} 5)$, before ( $\mathrm{t} 1$ and $\mathrm{t} 2$ ) and after introducing treatment ( $\mathrm{t} 3, \mathrm{t} 4, \mathrm{t} 5)$ and in relation to the CLA-ELISA results. The number of ibexes present in every handling or included in every group is shown (Ibexes).

again to negative at some time between $\mathrm{t} 2$ and $\mathrm{t} 4$. In the $M$. bovis ELISA, only one ibex displayed a temporary positive result in $\mathrm{t} 3$ and, in the MAP ELISA, none of the ibexes displayed antibodies against $M$. $a$. subsp. paratuberculosis.

TP, WBC, eosinophil and platelet cell counts increased (between one- and two-fold) whereas monocyte and basophil cell counts decreased (three-fold) from t0 to t1 (Figure 3). Both PCV and haemoglobin concentrations significantly increased (one-fold) from t2 to $\mathrm{t} 3$ (Figure 4). Table 3 illustrates the influence of both captivity and treatment in the physiological responses of ibexes.

All SAA values and most $\mathrm{Hp}$ values were under the limit of detection considered acceptable for interpretation. Only three samples displayed interpretable $\mathrm{Hp}$ values, which showed no significant correlation with any other variable. ASG values showed no significant differences according to time or lesions score or correlation with other parameters.

\section{Discussion}

This is the first outbreak of CLA reported in Iberian ibex and, to our knowledge, in any other wild ungulate population. However, the infection rate leading to this outbreak of disease was favoured by captivity, as evidenced by the increase of the antibody levels against C. pseudotuberculosis, casualties and casuistry of lesions. Stressinduced immunosuppression caused by captivity may have favoured disease severity. The treatment including both antibiotics and vaccination apparently prevented casualties and fistulas but was not reflected in the humoural immune response. The ibex displaying a positive status for antibodies against C. pseudotuberculosis at t0, when first captured in the wild, may have acted as a source of infection within the enclosure. In fact, this ibex was found dead seven months after being placed in captivity and CLA was diagnosed as the cause of death. Other ibexes with subclinical affectation could have gone unnoticed in the clinical exploration performed at t0. Once within the enclosure, ibexes developing visible clinical signs such as draining fistulas could have gone unnoticed for weeks between handlings, contaminating the environment due to the lack of daily on-site staff presence. Mutual grooming, head butting, inquisitive attitudes or the habit to scratch shoulders against hard surfaces, are typical behavioural characters of goats that increase the risk of contagion $[4,39]$, and other factors may have played a role in the evolution of this CLA outbreak as well. C. pseudotuberculosis displays high levels of survival in the environment [3] and the mechanical transmission of this bacterium by houseflies and other Diptera has been described in cattle and buffaloes $[1,10]$.

Lesion score is the only evidence of a clear health improvement after treatment administration in the ibexes of our study. This is also observed in other vaccine studies [40]. ELISA classified as positive some serum samples from ibexes without clinical lesions; most of these ibexes had suffered from the disease previously and had recovered. The two individuals where this condition was not confirmed could either have gone unnoticed between handlings, suffered a subclinical affectation or could have been false positive results. Hence, whenever available, the medical record is important to interpret the ELISA results. In addition, the clinical external examination performed in 
Table 3 MANOVA and specific ANOVA showing influence of lberian ibex captivity ( $t 0$ ibexes were in the wild, $t 1-t 5$ in the enclosure), and treatment ( $t 2$ and $t 3$, before and after treatment, respectively) on physiological parameters (i.e., haematological parameters and acute phase protein concentration) and anti-C.pseudotuberculosis antibody presence (i.e., Optical Density (O.D.) obtained by means of ELISA) as a canonical response

\begin{tabular}{|c|c|c|c|}
\hline MANOVA & Pillai s trace & F-value & P-value \\
\hline Early captivity (t0 vs t1) & 0.974 & 15.793 & 0.001 \\
\hline Long-term captivity (t0 vs t1-t5) & 0.818 & 10.284 & $3.468 \mathrm{e}-08$ \\
\hline Treatment (t2 vs t3) & 0.735 & 1.979 & 0.141 \\
\hline ANOVA & Mean SE (Min-Max) & F-value & P-value \\
\hline \multicolumn{4}{|l|}{ Early captivity } \\
\hline $\lg G(O . D)$. & & 37.993 & $6.352 \mathrm{e}-06$ \\
\hline t0 & $0.220 .02(0.16-0.4)$ & & \\
\hline t1 & $0.50 .04(0.22-0.7)$ & & \\
\hline Leukocytes (10 ${ }^{3}$ cells/ $/$ l) & & 5.338 & 0.032 \\
\hline t0 & $11.21 .33(5.56-21.98)$ & & \\
\hline t1 & 15.160 .86 (12.11-19.95) & & \\
\hline Platelets (10 ${ }^{3}$ cells/ul) & & 6.652 & 0.018 \\
\hline to & $260.8252 .41(46 \quad 563)$ & & \\
\hline $\mathrm{t} 1$ & $470.5558 .3(109 \quad 784)$ & & \\
\hline Monocytes $\left(10{ }^{3}\right.$ cells $\left./ \mu l\right)$ & & 7.370 & 0.014 \\
\hline to & $2.160 .58(0.6-6.2)$ & & \\
\hline t1 & $0.590 .15(0.2-2)$ & & \\
\hline Eosinphils $\left(10^{3}\right.$ cells $\left./ \mu l\right)$ & & 5.085 & 0.036 \\
\hline to & $3.130 .67\left(\begin{array}{ll}1 & 8.4\end{array}\right)$ & & \\
\hline t1 & $5.080 .72(1.8-10)$ & & \\
\hline Basophils (10 ${ }^{3}$ cells/ $\left./ \mu l\right)$ & & 10.604 & 0.004 \\
\hline to & $1.760 .37(0.6-5.2)$ & & \\
\hline t1 & $0.590 .05(0.4-1)$ & & \\
\hline Total Protein (g/dl) & & 15.952 & 0.001 \\
\hline to & $7.10 .13(6.4-7.9)$ & & \\
\hline t1 & $8.310 .27\left(\begin{array}{ll}7 & 9.6\end{array}\right)$ & & \\
\hline \multicolumn{4}{|l|}{ Long-term captivity } \\
\hline $\lg G(O . D)$. & & 10.432 & 0.002 \\
\hline to & $0.230 .03(0.17-0.4)$ & & \\
\hline $\mathrm{t1}-\mathrm{t} 5$ & $0.480 .03(0.196-1.37)$ & & \\
\hline Basophils (10 ${ }^{3}$ cells/pl) & & 56.797 & $1.644 \mathrm{e}-09$ \\
\hline to & $1.380 .13(0.6-1.7)$ & & \\
\hline $\mathrm{t} 1-\mathrm{t} 5$ & $0.610 .04(0.2-1.2)$ & & \\
\hline \multicolumn{4}{|l|}{ Treatment } \\
\hline Haemoglobin (g/dl) & & 4.689 & 0.041 \\
\hline t2 & $10.460 .46(7.7-13.2)$ & & \\
\hline t3 & $11.920 .49(8.6-13.6)$ & & \\
\hline PCV (\%) & & 5.061 & 0.034 \\
\hline t2 & 33.251 .54 (24.5-42.7) & & \\
\hline t3 & $38.331 .65(27.4-44.8)$ & & \\
\hline
\end{tabular}

ANOVA values illustrate statistically significant parameters associated with captivity and treatment effect.

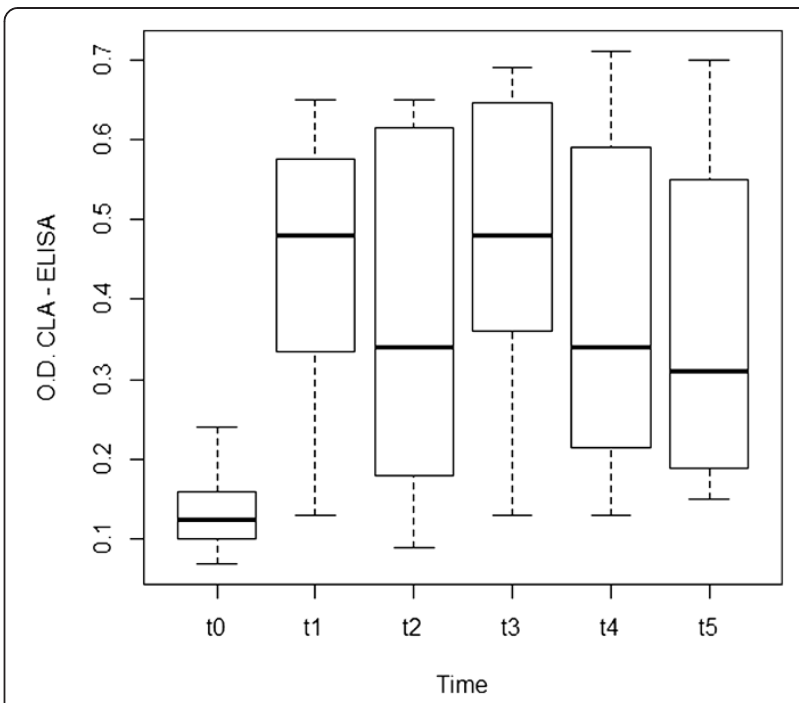

Figure 2 Box plot showing significant differences $\left(p=0.001^{* *}\right)$ between the mean optical density of the ibex CLA-ELISA processed samples at the moment of first capture in the wild ( $t 0)$ and in the subsequent handlings $(t 1, t 2, t 3, t 4, t 5)$.

the studied ibex population, based on the assessment of normality of lymph node size and swelling, may not be sensitive enough to detect animals with low grade lesions. The necropsied ibexes had abscesses, most frequently, in the lymph nodes of the anterior body part, which agrees with previous reports $[4,10,39,41]$. However, these studies did not observe a high percentage of visceral lesions $(66.7 \%$ in our study). Thus, improved methods for clinical assessment are needed. On the other hand, the ELISA also classified as negative an important percentage of clinically affected ibexes. Since CLA is a chronic condition, the ibexes in the initial phase of infection may not have had time to develop a detectable antibody response. This may have occurred in at least the three ibexes displaying more severe affectations and seroconverting later. However, false negative results derived from inadequate sensitivity cannot be discarded. The ELISA used was described as highly sensitive (98\%) and specific (100\%) in CLA-affected lambs [31]. These values were lower in our study. However, despite unknown sensitivity and specificity, ELISA is considered a suitable option for the detection of C. pseudotuberculosis infection in Iberian ibexes.

The lack of correlation between treatment and the humoural response contrasts with the increase in antibody levels observed in domestic small ruminants immunized with bacterin vaccines [42], toxoid-based vaccines [43] or combined vaccines [18]. Immunity against C. pseudotuberculosis is described as complex, involving both cellular and humoural immune responses. In the last several years, IFN- $\gamma$ and cytotoxic T-cells have been described as the main factors responsible 


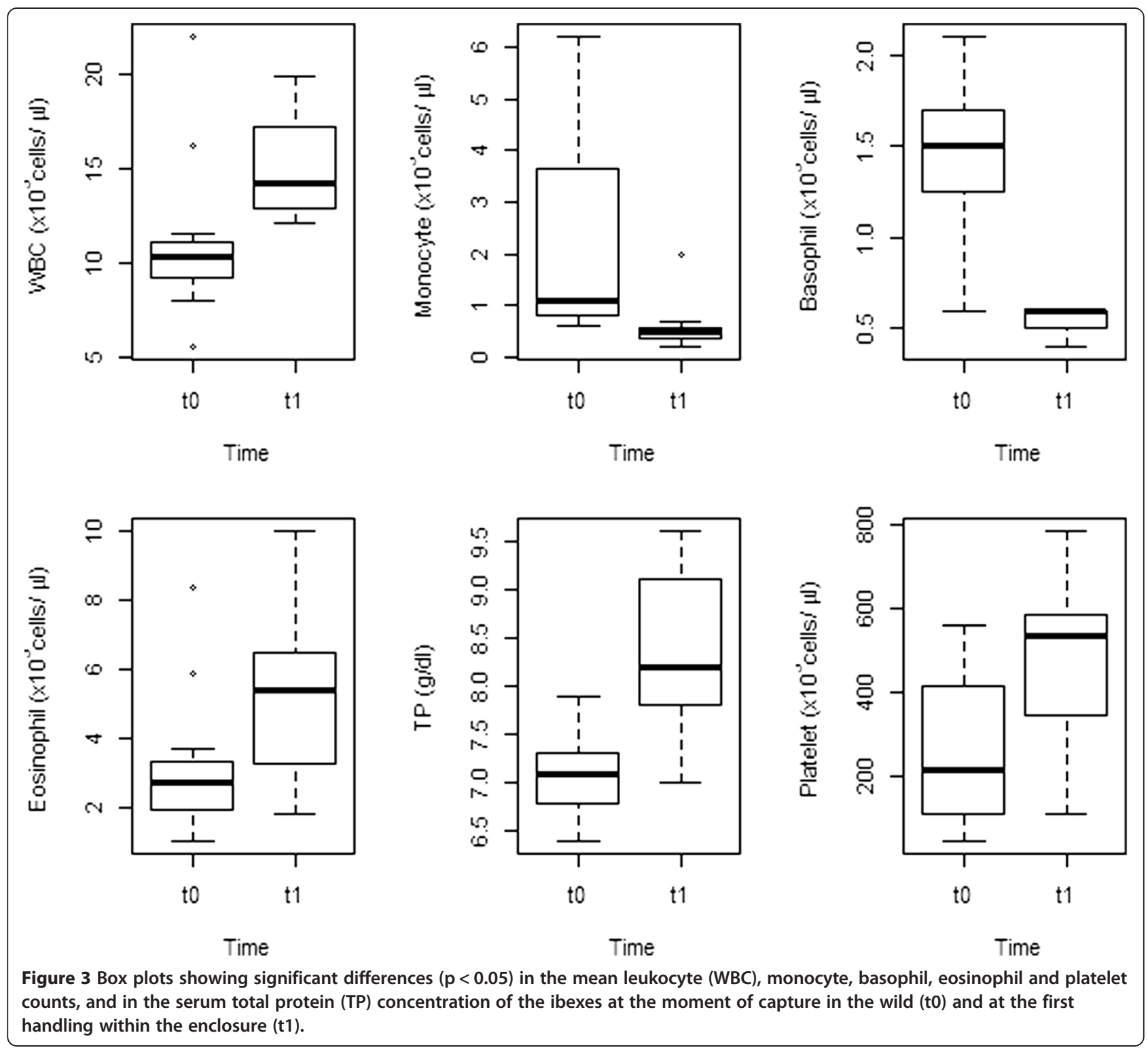

for the protection against C. pseudotuberculosis [40,44]. Therefore, the absence of an antibody response to vaccination may not be interpreted as a lack of vaccine effect. Aqueous adjuvants have been shown to diminish vaccine efficacy [45]. We cannot separate the effects of vaccines and those of antibiotics, as all the ibexes received both treatments and there was no control group. This was unavoidable as this was not a designed experiment, but a management intervention. However, the treated ibexes displayed significant health improvement at handlings $t 4$ and $t 5$, preceded by six months without any treatment. An antibiotic-only treatment is not expected to have such a long lasting effect, which indicates a vaccine effect. The lack of seroconversion in three ibexes suggests individual differences in immune response. However, a lack of sensitivity of the ELISA test used could also explain this. The possibility of cross-reactions with $M$. bovis and $M$. a. paratuberculosis $[3,46]$ was discarded with specific ELISAs. Previous studies have not found tuberculosis in Iberian ibexes from our study area $[47,48]$. Thus, the $M$. bovis ELISA positive ibex in this study is probably a false positive as other samples of the same ibex collected later displayed a negative result.

Apart from higher basophil and eosinophil cell counts, the mean haematological parameters of the ibexes included in our study were similar to the reference values previously described $[49,50]$. Basophils apparently decreased once in captivity but the factors determining the observed decrease are unclear. In fact, controversy 


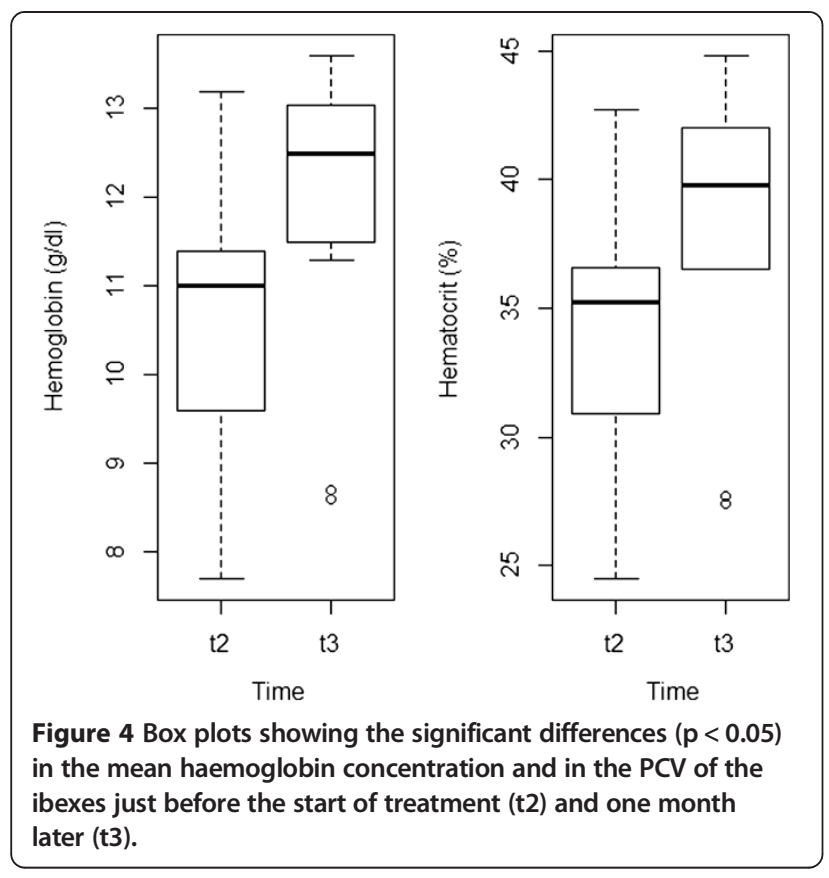

remains on the real factors determining basophil counts and this is a difficult-to-assess parameter in veterinary clinical pathology. Since it is a minority blood cell type, small differences in count may be observed as large variations. Hence, the observed differences could be due to differences in the capture and analytical methods. The increase of WBC and eosinophil cell counts could be related to both CLA (bacterial-induced leukocytosis) and higher parasite load derived from captivity conditions (parasite-induced eosinophilia). Parasite-induced eosinophilia is a well-known phenomenon [51,52]. Previous studies reported high prevalences and intensity of parasitosis by ixodides and helminthofauna in NGR Ports of Tortosa Beseit [53]. Coprology did not reflect a marked increase in parasitic load. Conversely, high tick loads were observed during handlings. Increased serum total protein concentration may reflect increased serum immunoglobulins (antibodies anti-C. pseudotuberculosis) and platelet counts may increase as a result of wounds caused by extremely high tick loads. Monocyte cell counts were also higher with regard to values previously published [49], which could be associated with stress induced by the box-trap capture method or to subclinical inflammatory conditions [54]. Although the leukogram is considered a useful tool for monitoring infectious processes, ruminants may show no or few changes even during severe infections [55]. Haemoglobin concentration and PCV increased from t 2 to $t 3$. This could be explained by an increased stress response due to proximity between $\mathrm{t} 2$ and $\mathrm{t} 3$ handlings, sensitization and increased catecholamine release in $\mathrm{t} 3$ [56]. However, it could also be due to the start of treatment in $\mathrm{t} 2$ and improved health of ibexes in $\mathrm{t} 3$.

The acute phase reaction is a physiological response to infection, inflammation, injuries or stress and includes the increase or decrease in the expression of a protein family called APP. Hence, the quantification of APP can be a way to determine the health status of an animal or a herd [57] and thus be used to assess disease pathogenesis, the evolution of an infection or the efficacy of drugs and vaccines. For example, CLA-affected sheep have been described to display higher serum concentrations of Hp, SAA and AGP $[55,58]$. Although the validation of analytical methods and reference values of SAA and Hp in Iberian ibex have been provided recently [33], we were not able to detect significant changes in Hp, SAA nor ASG. Hp and SAA have been proposed as major acute phase proteins in CLA-affected sheep and ASG is considered a moderate acute phase protein in chronic stages [58]. Although interspecific differences may exist, the frequency of sampling was lower in our study and changes in the APP concentration may have gone unnoticed due to the spaced sampling.

\section{Conclusion}

This is the first outbreak of CLA in Iberian ibex described in the literature, displaying high morbidity and mortality. However, captivity conditions had an important role over the course of the disease. This makes clear the need for improved methods for early detection of infected animals and quarantine protocols. The CLA-ELISA test used in the present study can be a useful tool for decision-making during quarantine management. However, sensitivity and specificity should be further assessed.

Treatment consisting of both vaccination and antibiotic therapy seemed to prevent mortality and alleviate disease severity, although this was not reflected by the humoural response. An experimental design aimed at differentiating the effect of vaccine from that of antibiotics was not possible in the present study. Despite the fact that time lapses between consecutive handlings (and treatments) point to a vaccine effect, an experimental design would be desirable if future studies are launched to assess vaccine efficacy.

\section{Competing interests}

The authors declare that they have no competing interests.

\section{Authors contributions}

AC JS LL GM conceived and designed the study. AC, ES, DG, EC, JL, SL and GM performed the ibex capture and handlings. RV performed necropsies and pathology. GM, JL, EC and AC did the haemathology. JS, AC and LL performed microbiology and the ELISA analyses. AC and ES performed the statistical analysis. CB and IG syntesized C. pseudotuberculosis autovaccine. EB designed and standardized APP protocols. AC, JS, ES and GM drafted the paper. All authors read and approved the final manuscript. 


\section{Acknowledgements}

E. Serrano was supported by the postdoctoral program (SFRH/BPD/96637/2013) of the Fundao para a Cincia ea Tecnologia, Portugal. We are grateful to Dr. Cuello and Dr. Gallego (Department of Animal Health, University of Murcia, Spain) for their collaboration in the production of the antigen used in the ELISA specific for C. pseudotuberculosis, and Dr. McNair (Agri-Food and Biosciences Institute, Stormont, Belfast, Northern Ireland, United Kingdom) for providing the recombinant protein MPB70 used in the ELISA specific for M. bovis.

\section{Author details}

'Servei d Ecopatologia de Fauna Salvatge (SEFaS), Departament de Medicina i Cirurgia Animals, Facultat de Veterinria, Universitat Autnoma de Barcelona (UAB), 08193 Bellaterra, Spain. ${ }^{2}$ Departamento de Sanidad Animal, Facultad de Veterinaria, Universidad de Murcia (Regional Campus of International Excellence Campus Mare Nostrum ), Murcia, Spain.

${ }^{3}$ Departamento de Sanidad Animal, Facultad de Veterinaria, Universidad de Crdoba - Agrifood Excellence International Campus (ceiA3), Crdoba, Spain. ${ }^{4}$ CESAM, Departamento de Biologia, Universidade de Aveiro, 3810-193 Aveiro, Portugal.

Received: 1 August 2014 Accepted: 25 November 2014

Published online: 10 December 2014

\section{References}

1. Dorella FA, Pacheco LGC, Oliveira SC, Miyoshi A, Azevedo V: Corynebacterium pseudotuberculosis: microbiology, biochemical properties, pathogenesis and molecular studies of virulence. Vet Res 2006, 37:201 218.

2. Selim SA: Oedematous skin disease of buffalo in Egypt. J Vet Med B Infect Dis Vet Public Health 2001, 48:241 258.

3. Windsor PA: Control of caseous lymphadenitis. Vet Clin North Am Food Anim Pract 2011, 27:193 202.

4. Baird GJ, Fontaine MC: Corynebacterium pseudotuberculosis and its role in ovine caseous lymphadenitis. J Comp Pathol 2007, 137:179 210.

5. Clark KA, Robinson RM, Weishuhn LL, Litton GW, Marburguer RG: Caseous Lymphadenitis in pronghorns (Antilocapra americana). J Wildl Dis 1972, 8:67 71.

6. Kelly EJ, Rood KA, Skirpstunas R: Abscesses in captive elk associated with Corynebacterium pseudotuberculosis, Utah, USA. J Wildl Dis 2012, 48:803 805 .

7. Tarello W, Theneyan M: Corynebacterium pseudotuberculosis and Corynebacterium renale isolated from two Arabian oryx (Oryx leucoryx). Vet Rec 2008, 162(26):862 863.

8. Mller B, de Klerk-Lorist L-M, Hent on MM, Lane E, Parsons S, van Pittius NCG, Kotze A, van Helden PD, Tanner M: Mixed infections of Corynebacterium pseudotuberculosis and non-tuberculous mycobacteria in South African antelopes presenting with tuberculosis-like lesions. Vet Microbiol 2011, 147:340 345.

9. Bartolom J, Roca MJ, Marcote E, Moreno R: Corynebacterium pseudotuberculosis adenitis in a shepherd. Med Clin (Barc) 1995, 104:699 701 .

10. Guimares ADS, Borges F, Pauletti RB, Seyffert N, Ribeiro D, Lage AP, Heinemann MB, Miyoshi A, Maria A, Gouveia G, Federal U, Gerais DM, Av U, Carlos A, Postal C, Cep U, Horizonte B, Gerais M: Caseous lymphadenitis: epidemiology, diagnosis, and control. IIOAB J 2011, 2:33 43.

11. Dercksen DP, Brinkhof JM, Dekker-Nooren T, Maanen K, Bode CF, Baird G, Kamp EM: A comparison of four serological tests for the diagnosis of caseous lymphadenitis in sheep and goats. Vet Microbiol 2000, 75:167 175

12. Menzies PI, Hwang Y-T, Prescott JF: Comparison of an interferon-gamma to a phospholipase $D$ enzyme-linked immunosorbent assay for diagnosis of Corynebacterium pseudotuberculosis infection in experimentally infected goats. Vet Microbiol 2004, 100:129 137.

13. Prescott JF, Menzies PI, Hwang Y-T: An interferon-gamma assay for diagnosis of Corynebacterium pseudotuberculosis infection in adult sheep from a research flock. Vet Microbiol 2002, 88:287 297.

14. Cameron CM, Minnaar JL, Engelbrecht MM, Purdom MR M: Immune response of merino sheep to inactivated Corynebacterium pseudotuberculosis vaccine. Onderstepoort J Vet Res 1972, 1:11 24

15. Fontaine MC, Baird G, Connor KM, Rudge K, Sales J, Donachie W: Vaccination confers significant protection of sheep against infection with a virulent United Kingdom strain of Corynebacterium pseudotuberculosis. Vaccine 2006, 24:5986 5996.

16. Menzies $\mathrm{Pl}$, Muckle CA, Brogden KA, Robinson L: A field trial to evaluate a whole cell vaccine for the prevention of caseous lymphadenitis in sheep and goat flocks. Can J Vet Res 1991, 55:362 366.

17. Menzies PI, Muckle CA, Hwang YT, Songer JG: Evaluation of an enzymelinked immunosorbent assay using an Escherichia coli recombinant phospholipase D antigen for the diagnosis of Corynebacterium pseudotuberculosis infection. Small Rumin Res 1994, 13:193 198.

18. Piontkowski MD, Shivvers DW: Evaluation of a commercially available vaccine against Corynebacterium Pseudotuberculosis for use in sheep. J Am Vet Med Assoc 1998, 212:1765 1768.

19. Hodgson AL, Krywult J, Corner LA, Rothel JS, Radford AJ: Rational attenuation of Corynebacterium pseudotuberculosis: potential cheesy gland vaccine and live delivery vehicle. Infect Immun 1992, 60:2900 2905

20. Len-Vizcano L, Garrido A, Gonzlez-Candela M, Cubero M: Clnica de la pseudotuberculosis. Ovis 2002, 78:63 76.

21. Acevedo P, Real R: Biogeographical differences between the two Capra pyrenaica subspecies, C. p. victoriae and C. p. hispanica, inhabiting the Iberian Peninsula: implications for conservation. Ecol Modell 2011, 222:814 823.

22. Alados CL, Montaana A, Box PO, Oria CH: Cabra Monts Capra Pyrenaica. Museo Nacional de Ciencias Naturales, Madrid 2012, 2008:8 10.

23. Herrero, J, Prez, J: Capra pyrenaica In: IUCN 2014. IUCN Red List of Threatened Species. Version 2014.2, 2008, [www.iucnredlist.org]

24. Acevedo P, Cassinello J: Biology, ecology and status of Iberian ibex Capra pyrenaica: a critical review and research prospectus. Mamm Rev 2009, 39:17 32.

25. Prez J: The dynamics of sarcoptic mange in the ibex population of Sierra Nevada in Spain influence of climatic factors. J Wild Res 1997 2:86 89 .

26. Verbisck G, Gonzalez-Candela M, Cubero MJ, Len L, Serrano E, Perales A: Mycoplasma agalactiae in Iberian ibex (Capra pyrenaica) in Spain. Vet Rec 2010, 167:425 426.

27. Prez JM, Serrano E, Gonzlez-Candela M, Len-Vizcaino L, Barber GG, de Simn MA, Fandos P, Granados JE, Soriguer RC, Festa-Bianchet M: Reduced horn size in two wild trophy-hunted species of Caprinae. Wildlife Biol 2011, 17:102 112

28. Casas-Daz E, Marco I, Lpez-Olvera J, Mentaberre G, Lavn S: Comparison of xylazine ketamine and medetomidine ketamine anaesthesia in the Iberian ibex (Capra pyrenaica). Eur J Wildl Res 2011, 57:887 893.

29. Fandos P: Factors affecting horn growth in male Spanish ibex (Capra pyrenaica). Mammalia 1995, 59:229 235.

30. Casas-Daz E, Marco I, Lpez-Olvera JR, Mentaberre G, Lavn S: Use of acepromazine for stress control in Spanish ibex (Capra pyrenaica) captured by drive-net. Vet J 2010, 183:332 336.

31. Solanet JJ, Malena R, Estein SM, Belchior SE, Paolicchi FA, Tract AB: Desarrollo de una prueba de ELISA para detectar anticuerpos en carneros vacunados o infectados con Corynebacterium pseudotuberculosis. Rev Argent Microbiol 2011, 43:9 17.

32. Buenda AJ, Navarro JA, Salinas J, McNair J, de Juan L, Ortega N, Cmara P, Torreblanca P, Sanchez J: Ante-mortem diagnosis of caprine tuberculosis in persistently infected herds: influence of lesion type on the sensitivity of diagnostic tests. Res Vet Sci 2013, 95:1107 1113.

33. Bach-Raich E: Acute phase proteins in wild boar, pyrenean chamois and spanish ibex: Method validation and reference values. PhD thesis. Universitat Autnoma de Barcelona; 2012

34. Eckersall PD, Saini PK, McComb C: The acute phase response of acid soluble glycoprotein, alpha(1)-acid glycoprotein, ceruloplasmin, haptoglobin and C-reactive protein, in the pig. Vet Immunol Immunopathol 1996, 3 4:377 385.

35. Winzler RJ: Determination of Serum Glycoproteins. In Methods of Biochemical analysis. Vol II. Edited by Glick DT. New York: Interscience Publishers, Inc; 1995:279 311

36. Nagahata $\mathrm{H}$, Taguchi $\mathrm{K}$, Noda $\mathrm{H}$ : Preliminary studies on the acid soluble glycoproteins in serum and their diagnostic value for acute inflammatory diseases in cattle. Vet Res Commun 1989, 13:257 263.

37. Tecles F, Fuentes P, Martnez Subiela S, Parra MD, Muoz A, Cern JJ: Analytical validation of commercially available methods for acute phase proteins quantification in pigs. Res Vet Sci 2007, 83:133 139. 
38. Hair J, Black W, Babin B, Andreson R: Multivariate Data Analysis. 7th edition. New Jersey: Prentice Hall Inc;; 2009.

39. Al-Gaabary MH, Osman SA, Oreiby AF: Caseous lymphadenitis in sheep and goats: clinical, epidemiological and preventive studies. Small Rumin Res 2009, 87:116 121 .

40. Bastos BL, Portela R, Dorella F: Corynebacterium pseudotuberculosis: immunological responses in animal models and zoonotic potential. J Clin Cell Immunol 2012, S4:005.

41. Williamson LH: Caseous lymphadenitis in small ruminants. Vet Clin North Am Food Anim Pract 2001, 17:359 371.

42. Sting R, Steng G, Spengler D: Serological studies on Corynebacterium pseudotuberculosis infections in goats using enzyme-linked immunosorbent assay. Zentralb/ Veterinarmed B 1998, 45:209 216.

43. Paton MW, Sutherland SS, Rose IR, Hart RA, Mercy AR, Ellis TM: The spread of Corynebacterium pseudotuberculosis infection to unvaccinated and vaccinated sheep. Aust Vet J 1995, 72:266 269.

44. Dorella FA, Pacheco LG, Seyffert N, Portela RW, Meyer R, Miyoshi A, Azevedo V: Antigens of Corynebacterium pseudotuberculosis and prospects for vaccine development. Expert Rev Vaccines 2009, 8:205 213.

45. Edelman R: An Overview of Adjuvant Use. In Vaccine Adjuvants, Volume 42. Edited by O Hagan D. New York: Springer; 2000:1 27.

46. Manning EJB, Cushing HF, Hietala S, Wolf CB: Impact of Corynebacterium pseudotuberculosis infection on serologic surveillance for Johnes disease in goats. J Vet Diagn Invest 2007, 19:187 190.

47. Mentaberre G, Serrano E, Velarde R, Marco I, Lavin S, Mateos A, de Juan L, Domnguez $\mathrm{L}$, Oliv $\mathrm{X}$, Romeva J: Absence of TB in Iberian ibex (Capra pyrenaica) in a high-risk area. Vet Rec 2010, 166:700.

48. Mentaberre G, Romero B, de Juan L, Navarro-Gonzlez N, V elarde R, Mateos A, Marco I, Oliv-Boix X, Domnguez L, Lavn S, Serrano E: Long-term assessment of wild boar harvesting and cattle removal for bovine tuberculosis control in free ranging populations. PLoS One 2014, 9:e88824.

49. Casas-Daz E, Lpez-Olvera JR, Marco I, Mentaberre G, Lavn S: Hematologic and biochemical values for Spanish ibex (Capra pyrenaica) captured via drive-net and box-trap. J Wildl Dis 2008, 44:965 972.

50. Prez JM, Gonzlez FJ, Granados JE, Prez MC, Fandos P, Soriguer RC Serrano E: Hematologic and biochemical reference intervals for Spanish ibex. J Wildl Dis 2003, 39:209 215.

51. Losson B, Detry-Pouplard M, Pouplard L: Haematological and immunological response of unrestrained cattle to Psoroptes ovis, the sheep scab mite. Res Vet Sci 1988, 44:197 201.

52. Timisjarvi J, Nieminen M, Saari E: Haematological values for reindeer. J Wild Manag 1981, 45:976 981.

53. Lavn S, Marco I, Rossi L, Meneguz PG, Vias L: Haemonchosis in Spanish ibex. J Wildl Dis 1997, 33:656 659.

54. Jain NC: Essentials of Veterinary Hematology. Philadelphia: Lea and Febiger; 1993

55. Bastos BL, Meyer R, Guimares JE, Ayres MC, Guedes MT, Moura-Costa LF, de Burghgrave US, Sena L, Azevedo V, Portela RW: Haptoglobin and fibrinogen concentrations and leukocyte counts in the clinical investigation of caseous lymphadenitis in sheep. Vet Clin Pathol 2011, 40:496 503.

56. Peinado VI, Fernandez-Arias A, Zabala JL, Palomeque J: Effect of captivity on the blood composition of Spanish ibex (Capra pyrenaica hispanica). Vet Rec 1995, 137:588 591.

57. Petersen HH, Nielsen JP, Heegaard PM: Application of acute phase protein measurements in veterinary clinical chemistry. Vet Res 2004, 35:163 187.

58. Eckersall PD, Lawson FP, Bence L, Waterston MM, Lang TL, Donachie W, Fontaine MC: Acute phase protein response in an experimental model of ovine caseous lymphadenitis. BMC Vet Res 2007, 3:35.

doi:10.1186/s13028-014-0083-x

Cite this article as: Colom-Cadena et al:: Management of a caseous lymphadenitis outbreak in a new Iberian ibex (Capra pyrenaica) stock reservoir. Acta Veterinaria Scandinavica 2014 56:83.

\section{Submit your next manuscript to BioMed Central and take full advantage of:}

$\otimes$ Convenient online submission

$\otimes$ Thorough peer review

$\nabla$ No space constraints or color $\nabla$ gure charges

$\otimes I m m e d i a t e$ publication on acceptance

Q Inclusion in PubMed, CAS, Scopus and Google Scholar

$\otimes$ Research which is freely available for redistribution

Submit your manuscript at www.biomedcentral.com/submit
C Biomed Central 